\title{
Interdisciplinaridade e conhecimento na sociedade em rede
}

\author{
Alzira Lobo de Arruda Campos* \\ Álvaro Cardoso Gomes** \\ Antônio Jackson de Sousa Brandão***
}

\begin{abstract}
Resumo
A dúvida cartesiana como método de pesquisa é vista como um paradigma para o diálogo metódico, na produção do conhecimento interdisciplinar ou para o pensar complexo, na sociedade em rede. A interdisciplinaridade, definida como uma das versões possíveis do método científico, é praticada há séculos por cientistas da mais variada natureza, embora compareça como novidade no mundo acadêmico. Interpretam-se tais dados à luz da lógica formal do conhecimento nas ciências sociais e nas humanidades, conferindo-se ênfase à teoria e à ciência dos modelos.
\end{abstract}

Palavras-chave: Interdisciplinaridade. Diálogo metódico. Conhecimento em rede.

\section{Interdisciplinarity and Web Knowledge}

\begin{abstract}
The Cartesian doubt as a research method is seen as a paradigm for the methodical dialogue in the production of interdisciplinary knowledge or for a more complex way of thinking, in the web society. Interdisciplinarity, defined as one of the possible versions of the scientific method, has been practiced for centuries by scientists of the most various natures, although many times it seems as something new in the academic world. This data is analyzed through the formal logic of knowledge in the Social Sciences and in Humanities fields, granting emphasis to the theory and to the science of models.
\end{abstract}

Keywords: Interdisciplinarity. Methodical dialogue. Web knowledge.

Recebido: 21/03/2017

Aceito: 03/10/2017

\footnotetext{
* Doutora em História, Livre-Docente pela UNESP, Professora Titular do Mestrado Interdisciplinar em Ciências Humanas da UNISA (Universidade de Santo Amaro, SP).

** Doutor e Livre-Docente em Letras pela Universidade de São Paulo, Professor Titular. Coordenador do Mestrado Interdisciplinar da Universidade de Santo Amaro.

*** Doutor em Letras pela USP; Professor titular do Mestrado Interdisciplinar em Ciências Humanas da UNISA (Universidade de Santo Amaro, SP).
} 


\section{Introdução}

Há mais de 300 anos, René Descartes apresentou a dúvida metódica como fundamento do seu Discurso do Método. No século passado, múltiplos autores têm adotado o diálogo metódico entre as mais variadas ciências como base de suas investigações. Na sociedade em rede, que tipifica o mundo contemporâneo, a pesquisa também em rede parece se legitimar como uma poderosa ferramenta para o avanço do saber. Trata-se de longo caminho, já suficientemente balizado, mas que permanece na zona brumosa dos equívocos frequentes, gerados no meio acadêmico, quando abordagens inovadoras são submetidas ao escrutínio de "pares". Em especial, quando as novidades sugeridas pressupõemse capazes de ameaçar poderes estabelecidos em territórios rigidamente delimitados, de acordo com normas emanadas da singularidade das "especializações".

Descartes, do mesmo modo que seus contemporâneos, não se preocupava com áreas científicas e com suas fronteiras. Os homens de ciência da época, munidos da conveniente erudição, interagiam com autores da mais diversa pelagem, intervindo em assuntos que considerassem adequados às suas inquietações de espírito, levados pela curiosidade e pelo ceticismo diante dos saberes estabelecidos. A dúvida e o ceticismo metódicos revolucionaram a maneira em voga de produzir ciência e libertaram as inteligências de saberes apriorísticos, tornados dogmas pela autoridade dos doutores da Igreja ou de autores clássicos. O Discurso do Método postula a dúvida metódica como base da investigação, rechaçando as verdades pré-concebidas como obstáculos ao avanço da ciência. Descartes assume, dessa forma, uma posição revolucionária, que marcou a pesquisa científica a partir de então, com o fim dos saberes subjugados à autoridade civil ou à eclesiástica.

Com novas roupagens, o encapsulamento dos saberes retornou quando as universidades modernas oitocentistas criaram guetos de especialidades, fortemente estruturados e defendidos contra incursões alienígenas. Nesse ambiente, a ignorância em relação aos demais setores do conhecimento erigiuse, muitas vezes, como brasão intelectual. Um equívoco, é claro. Na melhor das hipóteses, um pedantismo acadêmico, de longa duração, decorrente muito mais da luta pelo poder nas universidades do que propriamente do desenvolvimento da lógica interna das ciências. Na prática, os cientistas continuavam a trabalhar, entrecruzando conhecimentos provenientes de áreas distintas do saber. Apenas como ilustração, relembremos que Augusto Comte, ao inventar a Sociologia, concebida como a "Física Social", uniu, em teia, as diversas disciplinas, prolongando as ciências da natureza para a sociedade e sublinhando a irredutibilidade da realidade social a uma única explicação, de caráter unilinear. Seu Sistema de política positiva busca definir a posição da sociologia frente às demais ciências humanas e em relação às ciências da natureza, enriquecendo "o estudo positivo do conjunto das leis fundamentais próprias dos fenômenos sociais" com as conquistas da história e da etnografia. (BOURDÉ e MARTIN, [s.d.], p. 51-52).

Em todas as discussões sobre a interdisciplinaridade, a fronteira surge como conceito chave, pois se trata de demarcar zonas de controle, no mundo e na academia. Com efeito, as fronteiras, lugares de encontros e desencontros, têm sido cenário de conflitos constantes, mas também áreas em que os processos culturais adquirem seu máximo dinamismo. Assim como a história da humanidade marcou a construção, o cruzamento e a derrubada de fronteiras, a ciência avança por meio de constantes negociações fronteiriças. Na medida em que as sociedades se foram criando, os homens preocuparamse em construir linhas divisórias através das quais bordas inexistentes demarcaram territórios e possessões. Reunidos em grupos e associações, os humanos construíram divisões ou fronteiras como mecanismo de autodefinição e autolimitação (OPERÉ, 2016, p. 7). A fronteira é ambivalente, pois cria espaços e propicia contatos. Enquanto favorece as identidades individuais, restringe-as, posto que uma identidade não é um bloco preciso, mas que se vai formando num fluir constante. Daí que as fronteiras fechadas bloqueiem toda evolução e produzam processos de involução destinados ao 
esgotamento. Não obstante, com todos os problemas que acarretam, as fronteiras são inevitáveis e necessárias, pois exercem a tarefa de preservação de identidades e de valores culturais e tradicionais. Elas são uma superfície de fricção que mantém vigente a consciência coletiva. Operé fala sobre os primeiros povoadores que despertaram a consciência de um mundo dividido ou que havia que ser dividido, desenvolvendo um relato que pode ser lido como uma metáfora à teoria da ciência:

Em muito pouco tempo, a multiplicidade foi tanta, que os poucos e primeiros povoadores
deixaram de se entender, e falavam distintas línguas sem códigos em comum. A lenda da
Torre de Babel, pensada como um baluarte que salvaria a todos de um futuro extermínio,
resultou uma solução impossível. As línguas se converteram em barreiras, cujos códigos se
associaram a crenças, preconceitos e símbolos nacionais, construções tão necessárias como
artificiais. A diversidade cria fronteiras tanto como as fronteiras são fontes de diversidade.
Entretanto, as fronteiras como as sociedades não são estáticas e se reformulam e mudam
constantemente (OPERÉ, 2016, p. 8-9).

Na ciência, a existência de modelos fixos, centrados em linguagens altamente especializadas, passa a ser contestada nas últimas décadas, em especial quanto à existência de fronteiras indevassáveis para os não iniciados, que funcionam muito como as barreiras mencionadas no texto acima citado. Desse ponto de vista, a inter/transdisciplinaridade localiza-se nas áreas fronteiriças das ciências, criando novos objetos e novas abordagens. É o que tem sido descrito como o "pensar complexo", necessário a um mundo globalizado e em acelerado processo de mutação.

\section{0 conhecimento em rede ou o mercado comum das ciências do homem}

O século XX tratou de operar uma profunda revisão da unilinearidade proposta pela "ciência positiva", reconhecendo seus limites e propondo interações entre áreas científicas e métodos diversos. Uma posição pioneira face ao cientificismo do século anterior foi assumida pela revista Annales, fundada em 1929, a qual, seguindo a trajetória de seus diretores, Lucien Febvre e Marc Bloch, procurou edificar uma ciência histórica apoiada no conjunto das ciências do homem. Dessa forma procurou resolver uma crise geral das ciências do homem, detectada por Braudel (entre muitos), crise essa decorrente da acumulação de novos conhecimentos e da permanência de um "humanismo retrógrado e insidioso", incapaz já de lhes servir de ponto de referência. A solução para esse problema estaria na convergência das diferentes ciências, a ser operada no âmbito de um trabalho coletivo, “cuja organização inteligente ainda está por estabelecer" (BRAUDEL, 1958, p. 725-753). A partir desse ponto de vista, o essencial seria precisar a função e os limites de um modelo comum das ciências sociais, que permitisse que elas deixassem de discutir tanto sobre as suas recíprocas fronteiras e que tentassem antes traçar melhor "as linhas que pudessem orientar uma investigação coletiva e também os temas que permitiriam alcançar uma primeira convergência” (BRAUDEL, 1958, p. 42 e 69). O apelo, por fim, é pela formação de uma espécie de mercado comum das ciências do homem, apelo esse que, nas últimas décadas, sistematizou as interações que ocorriam entre as diversas disciplinas, definindo nova área do conhecimento, que se convencionou chamar de multi, inter ou transdisciplinar.

Como objetivo primordial, esse novo campo do conhecimento propôs a meta de atenuar ou derrubar mesmo os muros de disciplinas diferentes, eliminando o saber "em gavetas". Roland Barthes, cujo centenário de nascimento se comemora neste ano, alinha-se a esse movimento, ao inventar "uma nova forma de existência para o intelectual e o escritor ao dissolver a separação entre literatura, filosofia e outras áreas das ciências humanas" (MARTY, Ilustríssima, C8. Folha de S. Paulo, 22/11/2015). Nos dias em que vivemos, até as ditas ciências exatas, as biológicas ou as físico-naturais, apresentam as suas fronteiras em fermentação, como consequência direta ou indireta da complexidade dos problemas que nos atingem (e aos outros animais, às plantas, à paisagem). A esses problemas, estariam indicadas soluções também complexas, dificilmente atingíveis no espaço estrito das especializações. O diálogo 
impôs-se ao discurso do método. Não mais episodicamente, entre ciências principais e ciências propostas como auxiliares ou como uma conversa polida entre intelectuais, a transmitir informações sobre os seus saberes específicos — sempre intocáveis aos não iniciados. Nos tempos da sociedade em rede, o diálogo se apresenta como basilar ao método interdisciplinar de pesquisa, que abre mão de hierarquias disciplinares e permanece sensível a modificações de epistemas, conceitos, métodos e técnicas. Por meio da troca sistemática de informações, essa área abarca novos problemas, objetos e abordagens, inovando e renovando o saber científico.

De acordo com concepções que se tornaram usuais, a pesquisa unidisciplinar abrange um ramo apenas do conhecimento, diferentemente da multidisciplinaridade, a operar em rede de várias disciplinas, mas que se fecha à integração de conceitos ou métodos dos campos distintos do saber. Na mesma vertente, a interdisciplinaridade trabalha com uma rede aberta de disciplinas, mas se apresenta porosa às contribuições teóricas e metodológicas que uma pode oferecer à outra. A transdisciplinaridade, por último, usa uma rede ainda mais aberta, postulando a geração de novos conceitos e métodos e visando à ultrapassagem completa das fronteiras disciplinares. Desse ponto de vista, a transdisciplinaridade, embora irmanada à multi/interdisciplinaridade, é a única modalidade a assumir a produção de novos epistemas e conceitos na produção científica e a consignar uma atitude inovadora na formulação e solução de problemas, em atitude que tem sido reiterada em congressos mundiais e protocolada por declarações de princípios (PINTO, 2005, pp. 154-5). A pesquisa transdisciplinar, por meio de grupos de pesquisa e de autores isolados, é tocada profundamente por problemas da contemporaneidade, aprofundando, desse viés, as relações entre a prática social e a teoria científica, consideradas ferramentas essenciais para a produção do saber.

As categorias acima esboçadas são ainda imprecisas, mas é essa indefinição que explica, talvez, a atração que exercem sobre os pesquisadores. Categorias, é bom que se sublinhe, artificiais, uma vez que evidentemente elas se comunicam entre si. Portanto, fica problemático imaginarmos que contribuições disciplinares em rede possam ser encaminhadas apenas para um dos polos da produção do conhecimento (epistemológico, teórico, metodológico, experimental, técnico), com o fim de definir eixos dialógicos exclusivos para os componentes da tipologia adotada: multi, inter ou transdisciplinar. Para que esse procedimento pudesse ocorrer, teríamos que pressupor a existência de uma autonomia entre os diversos quadros utilizados pelo pesquisador, o que já foi tentado, com resultados que têm sido postos em dúvida, por numerosos autores.

Por outro lado, é preciso insistir que a interdisciplinaridade não se traduz como uma linguagem "marco zero" ou do "vale tudo", presente em um certo holismo difuso, que postula a anulação das diferenças existentes entre as áreas do conhecimento (DOMINGUES, 2005, p. 13). Quase ao avesso dessa posição, a interdisciplinaridade assume o jargão comum à ciência: o uso de argumentos convincentes e comprobatórios da hipótese defendida, o rigor em conceitos selecionados, a formulação de problemas relevantes de investigação.

A essência da interdisciplinaridade reside no caráter interlocutório de sua metodologia, como já se falou. É o que define a sua identidade. Nesse sentido, o seu percurso é marcado pelo ceticismo sobre a realidade unilinear do saber, quando postulada como versão metodológica única, fato que esclarece muito a respeito dos ataques que a atingem. Positivistas e interpretativistas, por exemplo, consideram que o espaço designado pela nova metodologia é improvável, à luz da configuração clássica das disciplinas. Flávio Romero Guimarães enumera alguns desses e de outros equívocos existentes a respeito da interdisciplinaridade (GUIMARÃES, 2002, p. 13). 


\section{Teoria e ciência dos modelos}

Para o estabelecimento de um modelo interdisciplinar adequado às ciências sociais, seria essencial, antes de mais nada, definir a sua função e os seus limites, a fim de evitar que certas iniciativas possam ser infladas em demasia.

Sabe-se que os modelos não passam de hipóteses, sistemas de explicação solidamente vinculados, de acordo com a regra da equação ou da função: isto é igual àquilo, ou determina aquilo. Uma realidade determinada é vista em companhia de outra, e entre ambas se colocam claramente relações constantes e estreitas. Ademais, o modelo estabelecido para um dado meio social deve poder ser aplicado a outros meios da mesma natureza, através do tempo e do espaço, assumindo, pois, um valor recorrente. Esses sistemas de explicação variam até o infinito, obedecendo ao temperamento, ao cálculo ou à finalidade dos usuários: simples ou complexos, qualitativos ou quantitativos, estáticos ou dinâmicos, mecânicos ou estatísticos. Esta última distinção, retirada de Lévi-Strauss, considera que o modelo mecânico reproduziria a própria medida da realidade diretamente observada, de pequenas dimensões, a afetar somente grupos minúsculos de homens; para as sociedades constituídas por grandes números de indivíduos, impõe-se o cálculo de médias, integrante do modelo estatístico. Os modelos são sempre discutíveis, uma vez que as realidades que observam se modificam na linha do tempo. Assim, a investigação deve ser feita voltando sempre da realidade social ao modelo, e deste àquela, fazendo com que o modelo seja sucessivamente ensaio de explicação, instrumento de controle, de comparação, verificação da solidez e da própria vida de uma dada estrutura estudada. A longa duração, inerente às estruturas, parece ser a linha mais útil para uma observação e uma reflexão comuns às ciências sociais (BRAUDEL, 1972, p. 85).

$\mathrm{Na}$ seara da antropologia, mas com enorme relevância para a generalidade das ciências sociais, Lévi-Strauss apresenta uma análise relevante sobre os fenômenos sociais de extrema duração, quase intemporal, ao verificar que os sistemas de parentesco se perpetuam todos, uma vez que não há vida humana possível além de uma certa taxa de consanguinidade, que obriga um pequeno grupo de homens a se abrir ao mundo exterior, como forma de sobrevivência. Daí decorre que a proibição do incesto é uma realidade de longa duração. De modo igual, os mitos, de lento desenvolvimento, também correspondem a estruturas de uma extensa longevidade, dos quais é preciso colecionar múltiplas versões, ordenando as suas variações e conseguindo verificar, abaixo delas, uma profunda articulação que as determine. É evidente que, para o historiador, essas macroexplicações completam-se com as microexplicações próprias de uma observação sobre as diferenças existentes entre as diferentes versões do mito, consideradas significativas para o entendimento da época, do local e de seus autores.

Lévi-Strauss explica que a linguagem ou a ciência da comunicação em toda a sociedade realiza-se em três níveis: comunicação das mulheres; comunicação dos bens e dos serviços; comunicação das mensagens. Podemos admitir que, em níveis diferentes, sejam linguagens e, como tais, podem nos conceder o direito de analisá-las à luz dos progressos importantes da linguística ou da fonologia, que têm a desempenhar uma função renovadora nas ciências sociais, do mesmo modo, por exemplo, que a física nuclear fez para com o conjunto das ciências exatas (LÉVI-STRAUSS, 1958, p. 91).

A respeito dessa análise, Braudel observa que nada é mais didático do que ver Lévi-Strauss reduzir os mitos a uma série de células elementares, os mitemas, e a linguagem dos livros de cozinha a gustemas, buscando níveis em profundidade, subconscientes: enquanto falo não me preocupo com os fonemas de meu discurso; enquanto como, tampouco me preocupo com os gustemas. Mas em ambos os casos, "o jogo das relações sutis e precisas me acompanha". E termina com uma interrogação sobre se a investigação sociológica buscaria, como último grito, apreender as relações simples e misteriosas presentes sob todas as linguagens, a fim de as traduzir numa universal linguagem matemática, um "alfabeto Morse", como nova ambição das novas matemáticas sociais (BRAUDEL, 1972, p. 93). 
As discussões sobre o esgotamento de modelos teóricos ou metodológicos fazem parte da rotina acadêmica, que tem sido, nos últimos tempos, colocada diante do fim da realidade unilinear. Como regra geral, o retorno da narrativa nas ciências sociais remete à questão dos grandes modelos de análise, assim como do privilégio dado a escalas macrológicas e ao tratamento quantitativo dos dados. A sociologia oferece, a respeito, um bom exemplo, pelo qual a oposição entre quantitativo e qualitativo pode ser ilustrada na alternativa entre pesquisa analítica e pesquisa narrativa, que estrutura hoje a maior parte das interações e das tomadas de posição no mundo profissional. Quando se estuda a questão dos recursos narrativos no conhecimento histórico, diagnosticado em 1979 por Lawrence Stone, Jacques Revel relembra que o debate é quase tão velho quanto a historiografia ocidental. Desde os inícios da história grega, o gênero histórico abrangeu a associação entre uma operação de conhecimento e uma forma literária. A indistinção entre o modo narrativo e a redução da história a sua composição factual constitui o princípio da oposição entre ciência e literatura, proposto, entre outros, por François Simiand, que levou a palavra durkheimiana às áreas da história e da geografia, visando a desqualificar o modo de exposição literária, por muito tempo privilegiado pelos historiadores. $\mathrm{O}$ projeto de uma história "científica" postulou a necessidade de se construir rigorosamente os fatos a partir de uma hipótese, depois, proceder-se a uma validação empírica dessa construção, para que a história pudesse atender aos critérios da cientificidade, escapando de ser avaliada como um gênero literário. O novo cenário, proposto por Simiand, opôs a construção analítica (construída em geral sobre séries) à narração (montada sobre a singularidade do acontecimento), e tornou-se dominante na historiografia (SIMIAND, 1903, pp. 129-157). Por decênios, esse modelo foi hegemônico na produção historiográfica.

É preciso que se declare, no entanto, que os modelos históricos, isto é, aqueles fabricados por historiadores, são bastante elementares e rudimentares; raras vezes chegam ao rigor de uma verdadeira regra científica e quase nunca se preocupam em desembocar numa linguagem matemática revolucionária. O modelo braudeliano de longa duração aproxima-se aos modelos prediletos, quase intemporais das "matemáticas sociais", expressão ampla que abriga as teorias e as linguagens da informação, a comunicação ou as matemáticas qualitativas. Não obstante, Braudel nota faltar muito para que os historiadores ocupem posições de vanguarda nesse terreno, pois seus modelos não passam de feixes de explicações (BRAUDEL, 1972, p. 88).

As matemáticas sociais implicam, pelo menos três linguagens, susceptíveis de se misturar e de não excluir continuações: 1) a dos fatos necessários (dado um fato, o outro é consecutivo) traduz o campo das matemáticas tradicionais; 2) a linguagem dos fatos aleatórios, que é, desde Pascal, o campo do cálculo de probabilidades; 3) a linguagem, por fim, dos fatos condicionados, isto é, daqueles submetidos a regras de jogos, a suas estratégias. Em razão do uso dos conjuntos, dos grupos e do próprio cálculo das probabilidades, a estratégia dos jogos abre o caminho às matemáticas qualitativas. A partir desse momento, a passagem da observação à formulação matemática não usa já a intrincada via das medidas e dos longos cálculos estatísticos, mas se pode passar diretamente da análise social a uma formulação matemática. Braudel exemplifica como esse novo mecanismo matemático funciona em uma pesquisa social:

Até agora, o tratamento prévio [da pesquisa] tem sido praticamente sempre o mesmo: escolher uma unidade restrita de observação, como, por exemplo, uma tribo "primitiva" ou uma unidade demográfica "fechada", na qual quase tudo seja examinável e tangível; estabelecer, depois, entre os elementos distintos, todas as relações, todos os jogos possíveis. Estas relações rigorosamente determinadas subministram as equações das quais as matemáticas haverão de tirar todas as conclusões e prolongamentos possíveis, para culminar em um modelo que reúna a todas elas ou, dito com mais exatidão, que as tome a todas elas em conta (BRAUDEL: 1972, p. 90). 
Há aproximadamente quarenta anos, o abalo sofrido por certezas estruturalistas conduziu historiadores, como os antropólogos, a se interrogar sobre suas maneiras de produzir nos moldes preconizados por Durkheim e Simiand. Desse modo, a distinção vista como natural entre quantitativo e qualitativo, entre análise e descrição, transformou-se em objeto de uma dúvida radical. A sociologia ficou por muito tempo fora desse questionamento, talvez porque a forma dominante de sua prática tenha contemplado, nos últimos decênios, modos de análise que resultam naquilo que se chama de técnica mista em história da arte e que associa, num quadro analítico estrutural, formas narrativas mais tradicionais e elementos formalizados, com o objetivo essencialmente ilustrativo. O exemplo mais célebre está em A distinção, de Pierre Bourdieu (BOURDIEU, 1979). Essa sociologia do gosto põe em presença conjunta uma narração sociológica e dados de pesquisa, sem se preocupar com uma interpretação estruturante e geral entre ambos.

Note-se que as oposições entre análise e narrativa, entre quantitativo e qualitativo têm sido alvos de um profundo questionamento, tendo em conta que as distinções têm uma forte significação institucional, definindo linhas de clivagem muito nítidas no universo profissional e opondo lugares, trajetórias e estilos, numa metodologia que permite opor certo número de pares (quantitativo/ qualitativo, positivismo/interpretação, análise/narrativa, realismo/construtivismo, estrutura social/ cultura, nível indivíduo/nível emergente, saber transcendente/saber situado). Entre esses pares, sublinhe-se a dicotomia absoluta que constitui a oposição entre a associação do positivismo e da análise, de um lado, e a da narrativa e da interpretação, de outro. Esse fenômeno se fortalece principalmente na vertente institucional da organização dos saberes, isto é, da partilhas das tarefas, da identificação dos lugares de formação e no reconhecimento imediato de um estilo profissional e de uma afiliação metodológica. Jean-Louis Fabiani ilustra essa metodologia com modos de produção adotados pela sociologia, na França, nos últimos trinta anos. Diz ele que nesse espaço de tempo, sem muito esforço de reflexão, privilegiaram-se formas de análise que provêm daquilo que se chama de técnica mista em história da arte e que associam, num quadro analítico estrutural, modos narrativos de elaboração tradicional e elementos formalizados, num prisma essencialmente ilustrativo. O modelo preferencial de exposição em sociologia conjuga, de maneira mais ou menos independente, uma descrição sociológica a dados de pesquisa, cujas condições de produção são anexadas, em caráter ilustrativo, e levantadas a partir de corpora heterogêneos e de trechos de entrevistas. Nesse esquema, uma boa parte do trabalho de interpretação é deixada ao leitor, que não identifica necessariamente as lacunas entre a descrição e a análise, com as quais é confrontado. O epistemocentrismo acentuado da sociologia francesa e a relação lancinante do dever de "vigilância epistemológica" não suprimiram um certo número de nós cegos. Foi, paradoxalmente, a disciplina menos reflexiva e a mais explicitamente narrativa, a história, que levantou as questões mais pertinentes sobre os modos de produção do saber, relativamente às formas de exposição (FABIANI, 2003, p. 550).

É preciso que se aluda, ainda, ao materialismo histórico, dada a sua importância para sistemas explicativos das mais variadas disciplinas. O seu fundador, Karl Marx, filósofo, historiador, sociólogo, jornalista, mas sobretudo um economista genial, criou um modelo que, em linhas gerais, continua a ser aplicado até nossos dias, com o abandono de seu providencialismo filosófico. Sartre se indispõe contra a rigidez, o esquematismo e a insuficiência do modelo, em detrimento do individual e do particular. Na verdade, o marxismo comporta um mundo de modelos. Braudel, fazendo eco a numerosos hermeneutas do marxismo, declara não se colocar contra o modelo, mas sim contra o uso que dele se faz, acrescentando:

O gênio de Marx, o segredo de seu prolongado poder, provém de que foi o primeiro a fabricar verdadeiros modelos sociais e a partir da longa duração histórica. Porém esses modelos têm sido imobilizados em sua simplicidade, concedendo-se-lhes um valor de lei, de explicação prévia, automática, aplicável a todos os lugares, a todas as sociedades; enquanto que se fossem devolvidos às águas cambiantes do tempo, sua trama se poria de manifesto porque é sólida e 
está bem tecida: reapareceria constantemente, porém matizada, umas vezes esfumada e outras vivificada pela presença de outras estruturas, susceptíveis, elas também, de ser definidas por outras regras e, portanto, por outros modelos (BRAUDEL, 1972, p. 103).

A longa citação acima se justifica, pois interpreta a mais poderosa análise do século XIX, deixando claro que a esclerose dogmática do modelo marxista foi determinada pelo uso esquemático que dele foi feito, limitando o seu poder criador. Em conclusão ao seu pensamento, diz Braudel: "Quase posso acrescentar que o marxismo atual me parece ser a própria imagem do perigo que ronda a toda ciência social, enamorada do modelo em bruto, do modelo pelo modelo.” (BRAUDEL, 1972, p. 104).

\section{A etnometodologia e o "pensar complexo"}

As discussões gerais sobre os caminhos metodológicos na produção do saber, que põem ênfase na insuficiência de modelos já rotinizados pela prática unilinear das disciplinas, configuram o eixo da teoria da interdisciplinaridade. Trata-se de uma área que adota como modelo de abordagem a interlocução sistemática entre as múltiplas ciências, respeitando os seus jargões respectivos, mas permanecendo porosa a inovações em todos os polos do conhecimento - epistemológico, teórico, metodológico, técnico. A interdisciplinaridade caracteriza-se, ademais, pela plasticidade metodológica e pelo abandono da unilinearidade como representação da sociedade, assumindo o pressuposto de que não há metodologia ou teoria únicas, capazes de dar conta, por si sós, da complexidade dos problemas que se apresentam à sociedade e aos diferentes campos do saber, em nossos dias (FERNANDES; ROMERO; BRASILEIRO, 2002, p. 9-10).

A interdisciplinaridade acompanha a lógica da produção científica na procura de um modelo de abordagem que fuja a padrões de autonomia metodológica, modelo esse que se poderia intitular, bem ou mal, de uma etnometodologia. A recusa em aceitar modelos apriorísticos ou axiomas científicos encaminha-se para a configuração de um método original e para as condições de produção do conhecimento de acordo com um pensar complexo (DOMINGUES, 2005, p. 17).

Em ampla proporção, o nascimento da interdisciplinaridade decorreu do ceticismo e da descrença sobre a capacidade das ciências em levantar problemas e procurar suas soluções no campo fortemente estruturado dos departamentos universitários, com as suas poderosas especializações.

Nas ciências sociais, o fenômeno acima delineado pôs em discussão algumas posturas metodológicas consideradas definitivas pelo mundo universitário.

De todo modo, a divisão tomada como natural entre quantitativo e qualitativo, entre análise e descrição pode ser objeto de uma dúvida radical. A linearidade de um encaminhamento intelectual que desenvolveria através dos tempos a impecabilidade de uma baliza teórica colocou-se em questão, uma vez que a conclusão do trabalho não é jamais aquilo que se imaginava na origem. A biografia intelectual de numerosos cientistas demonstra a sinuosidade das escolhas que acabaram por suportar seus investimentos de pesquisa. Andrew Abbott, por exemplo, deixou-se atrair pela história, literatura e álgebra, antes de se decidir pela sociologia, pelo seu caráter disponível para a plasticidade. A sua tese de doutorado misturou quatro frentes de pesquisa, renovando profundamente o domínio da pesquisa e as questões relativas à estrutura temporal dos objetos sociais. Ao não encontrar, perto de seus colegas historiadores e sociólogos, verdadeiras respostas a seus problemas de investigação, Abbott voltou-se para outros saberes ou disciplinas, que abrangem da teoria literária à biometria, não cessando de bricolar ferramentas metodológicas susceptíveis de serem ajustadas aos objetos de que trata. A sua tese sobre profissões e competências deu lugar, em 1988, à publicação de The System of Professions, obra que renovou profundamente esse domínio de pesquisa e as questões relativas à dimensão temporal dos objetos sociais (FABIANI, 2003, p. 554). 
A teoria "fractal"4 proposta por Abbott busca entender as oposições teóricas e metodológicas nas ciências sociais, permitindo constatar que essas divisões se reproduzem também no interior dos campos: assim o marxismo pode desenvolver em seu seio oposições que o estruturam entre um saber de tipo narrativo (o desenvolvimento do capitalismo, como um fenômeno singular) e um saber de tipo analítico (FABIANI, Annales, 58e., nº 3, p. 549- 552).

Da mesma forma que Abbott, outros autores interrogam-se cada vez mais sobre o futuro dos métodos em ciências sociais. Uma das questões refere-se à análise da causalidade, fundamentada sobre o exame das relações de dependência entre variáveis, que foi considerada como refratária à imaginação sociológica, reducionista e portadora de ilusões sobre os modos de estruturação social. Nos últimos quarenta anos, tem-se fortalecido a crítica ao paradigma das variáveis, entendidas como entidades fixas, segundo a qual a sociedade corresponderia perfeitamente ao recorte que a escolha de variáveis instituiu. Essa crítica tem em conta a historicidade das formas de interações, complexas e pouco permeáveis à interpretação algébrica da vida em sociedade. Não obstante, o paradigma das variáveis persistiu nas formas de produção do conhecimento até data recente.

A ilusão da existência real de um mundo social constituído por um sistema de relações entre variáveis é a conclusão de um processo de descontextualização equivalente à independência da metodologia frente à teoria, operada quando a análise causal pretendeu encarnar a integralidade da realidade social. A partir desse dado, o arsenal metodológico ocupou todo o espaço da teoria, tornando impossíveis as idas e vindas entre o campo e a teoria, que constituem o cerne da argumentação sociológica. Como decorrência, surgiram múltiplas subespecialidades nas ciências sociais, largamente desconectadas entre si. Esse fato levou Abbott a considerar que o paradigma das variáveis teria perdido definitivamente a sua capacidade de orientar as ambições do saber sociológico. Haveria a necessidade de um motor próprio da pesquisa sociológica, que não possa ser reduzido à aplicação de procedimentos técnicos, por mais refinados que eles sejam (FABIANI, Annales, 58e., no 3, p. 547550).

A autonomização metodológica aprofundou a divisão entre os empiristas quantitativistas e os teóricos nas ciências sociais. Os primeiros adquiriram uma posição dominante nas revistas acadêmicas, na medida em que representam o lado mais institucional da profissão. Os segundos, sempre associados a pesquisas qualitativas, desenvolveram espaços de discussão sem intersecção com as formas dominantes do exercício disciplinar. De outro lado, a teoria desenvolvida aparenta-se com a filosofia social, a literatura ideológica ou à reciclagem "pomposa e vã" da filosofia desconstrutivista ou da teoria literária. A realidade linear geral transpôs um modelo matemático de transformação linear para a ordem das representações da sociedade, que tomou como certas algumas variáveis dependentes de variáveis antecedentes, sem entretanto esclarecer qual seria essa causalidade. Para que esse modelo fosse utilizável para fins de representação da sociedade, seria preciso, de acordo com Abbott, cartografar a sociedade em termos de álgebra linear. Esse processo suporia um mundo social exclusivamente composto de entidades fixas (as unidades de análise), providas de atributos (as variáveis). Estas últimas interagiriam, para produzir efeitos mensuráveis, como atributos de entidades fixas. O modelo supõe que a ordem das coisas não tem influência sobre a maneira como elas se revelam (FABIANI: Annales, 58e., no 3, pp. 549- 552).

A situação que prevalece no mundo universitário atual é a da coexistência de abordagens quantitativa e qualitativa, embora se constate a manutenção das fronteiras entre positivistas e narrativistas.

\footnotetext{
$4 \mathrm{O}$ termo é matemático e indica uma estrutura geométrica complexa cujas propriedades, em geral, repetem-se em qualquer escala.
} 


\section{Considerações finais}

As reflexões sobre a autonomização da metodologia diante da teoria conduzem à postulação de modelos híbridos, que unam sociologia, história, literatura e outras ciências, além de técnicas variadas, a um espaço de inovação, considerado o mais promissor para a pesquisa nas ciências sociais e nas humanidades. Portanto, a um espaço interdisciplinar, que acolha o retorno da narrativa, as explicações teóricas e a possibilidade de formalizar o diálogo metódico como eixo fundamental da produção do saber.

Uma das preocupações constantes dessa nova/velha área é a de encorajar a adoção de novos tipos de questionamentos e de abordagens, sem os destruir sob problemas metodológicos insuplantáveis (muitas vezes falsos). Roland Barthes tece algumas considerações a esse respeito, que merecem ser reproduzidas:

Alguns falam do método com gulodice, com exigência... ele não lhes parece jamais muito rigoroso, muito formal. O método torna-se uma Lei, mas como esta Lei é privada de todo efeito que lhe seja heterogêneo (ninguém pode dizer o que é, em "ciências humanas", um "resultado"), ele é infinitamente decepcionante... Assim, é constante que um trabalho que proclama sem cessar sua vontade de método seja finalmente estéril: tudo se passou no método, nada resta à escritura, o pesquisador repete que seu texto será metodológico, mas esse texto não vem nunca: nada mais seguro para matar uma pesquisa e a fazer se juntar ao grande estoque dos trabalhos abandonados, nada mais seguro que o método... [é preciso] num certo momento voltar-se contra o método... (BARTHES, 1969 apud ROBIN, 1973, p.8).

Essas palavras nos advertem que a vigilância metodológica excessiva, por um equívoco mal entendido, pode vir a matar a pesquisa, indo de encontro aos desígnios da área inter/transdisciplinar, empenhada em estimular e abrir novos horizontes aos estudos sociais e às humanidades. Como um efeito simétrico a essa preocupação, é preciso que os pesquisadores conservem-se atentos contra posições teórico-metodológicas precipitadas, contra questões e recursos conceituais falsos ou empréstimos metafóricos que possam conduzir a impasses. Enfim, contra artefatos metodológicos, habilmente construídos, que possam ser capazes de vir a demonstrar qualquer coisa, numa área que tem, em sua imprecisão, o seu lado mais atraente, mas na qual repousa também o seu maior risco. 


\section{Referências}

BOURDÉ, Guy e MARTIN, Hervé. As escolas históricas. [s.l.p.]: Publicações Europa-América, [s.d.].

BOURDIEU, Pierre. La distinction. Critique sociale du jugement. Paris: Éditions de Minuit, 1979.

BRAUDEL, Fernand. Histoire et sciences sociales: "la longue durée". Annales E. S. C., no 4, oct.dic. 1958, Débats et Combats, pp. 725-753.

BRAUDEL, Fernand. História e Ciências Sociais. Trad. de Carlos Braga e Inácia Canelas. Lisboa: Ed. Presença, 1972.

BRAUDEL, Fernand. La historia y las ciencias sociales. Madrid: Alianza Editorial, 1972.

DOMINGUES, Ivan (org.). Conhecimento e transdisciplinaridade II. Aspectos metodológicos. Belo Horizonte: Editora da UFMG: 2005.

FABIANI, Jean-Louis. Pour en finir avec la réalité unilinéaire. Le parcours méthodologique de Andrew Abbott. Annales. Histoire, Sciences Sociales. 58e. année, n. 3, mai-juin 2003.

GUIMARÃES, Flávio Romero. Um novo olhar sobre o objeto da pesquisa em face da abordagem interdisciplinar na pós-graduação. In: FERNANDES et al. (Org.) O fio que une as pedras: a pesquisa interdisciplinar na pós-graduação. São Paulo: Ed. Biruta, 2002.

LÉVI-STRAUSS, Claude. L'Anthropologie structurale. Paris: Plon, 1958.

MARTY, Éric, apud: EICHENBERG, Fernando. O amor à linguagem. Reflexões sobre Roland Barthes, 100. Ilustríssima, C8. Folha de S. Paulo, 22/11/2015.

OPERÉ, Fernando. Relatos de cautivos en las Américas desde Canadá a la Patagonia: siglos XVI al XX. Buenos Aires: Corregidor, 2016.

PINTO, Paulo Roberto Margutti. Lógica e Transdisciplinaridade. In DOMINGOS, Ivan. (Org). Conhecimento e Transdisciplinaridade II. Aspectos metodológicos. Belo Horizonte: Editora da UFMG, 2005, p. 137-168.

ROBIN, Regine. Histoire et linguistique. Paris: Armand Colin, 1973. 
